\title{
Retraction Note to: Capacity balancing for vanadium redox flow batteries through electrolyte overflow
}

\author{
Katharina Schafner ${ }^{1,2}$ (D) Maik Becker ${ }^{1,2} \cdot$ Thomas Turek $^{1,2}$
}

Published online: 10 July 2020

๑) Springer Nature B.V. 2020

\section{Retraction to: Journal of Applied Electrochemistry (2018) 48:639-649 https://doi.org/10.1007/s10800-018-1187-1}

The authors have retracted this article [1] because new results have shown that the assumption of a hydraulic convection through the membrane was not correct. It is very likely that the membrane used for the experiments in this article was damaged. As a result, a part of the determined model parameters and the simulation results changed after evaluation of new experimental results. The authors intend to publish a corrected version of their findings. All authors agree to this retraction.
The original article can be found online at https://doi.org/10.1007/ s10800-018-1187-1.

\section{Katharina Schafner}

katharina.schafner@alumni.tu-clausthal.de

1 Institute of Chemical and Electrochemical Process Engineering, Clausthal University of Technology, Leibnizstr. 17, 38678 Clausthal-Zellerfeld, Germany

2 Energy Research Centre of Clausthal University of Technology (EFZ), Am Stollen 19A, 38640 Goslar, Germany

\section{Reference}

1. Schafner K, Becker M, Turek T (2018) Capacity balancing for vanadium redox flow batteries through electrolyte overflow. J Appl Electrochem 48:639-649. https://doi.org/10.1007/s 1080 0-018-1187-1

Publisher's Note Springer Nature remains neutral with regard to jurisdictional claims in published maps and institutional affiliations. 